BMJ Open

Sport \&

Exercise

Medicine

\section{Elite athletes get pregnant, have healthy babies and return to sport early postpartum}

To cite: Sundgot-Borgen J, Sundgot-Borgen $C$, Myklebust G, et al. Elite athletes get pregnant, have healthy babies and return to sport early postpartum. BMJ Open Sport \& Exercise Medicine 2019:5:e000652. doi:10.1136/ bmjsem-2019-000652

Accepted 3 November 2019

Check for updates

(c) Author(s) (or their employer(s)) 2019. Re-use permitted under CC BY-NC. No commercial re-use. See rights and permissions. Published by BMJ.

'Department of Sports Medicine, The Norwegian School of Sport Sciences, Oslo, Norway

${ }^{2}$ Department of Sports Medicine The Norwegian School of Sport Sciences, Oslo, Norway

${ }^{3}$ The Norwegian School of Sport Sciences, Department of Sports Medicine, Oslo Sport Trauma Research Center, Oslo, Norway ${ }^{4}$ Faculty for Health and Sport Sciences, University of Agder, Kristiansand, Norway

Correspondence to Dr Jorunn Sundgot-Borgen; Jorunn.Sundgot-Borgen@nih.no

\section{ABSTRACT}

Objectives To enhance knowledge on pregnancy and return to sport in the postpartum period in elite female athletes.

Methods 34 Norwegian elite athletes (33.1 years) and 34 active controls ( 31.5 years) were asked about training and competitive history, pregnancy-related issues, injuries, body dissatisfaction (BD), drive for thinness (DT), eating disorders (ED) and practical experiences, through a questionnaire and interview. Independent samples T-tests or $\chi^{2}$ tests for between-group differences and paired-samples T-tests and repeated measures analysis of variance for within group differences were used.

Results No group differences in fertility problems, miscarriage, preterm birth or low birth weight were found. Both groups decreased training volume all trimesters and the first two postpartum periods compared with prepregnancy, and more athletes returned to sport/exercise at week 0-6 postpartum. We found no group differences in complications during pregnancy and delivery, but athletes reported fewer common complaints. Four athletes experienced stress fracture postpartum. Athletes had higher BD and DT postpartum, while controls reduced DT score. Number of athletes with clinical ED was reduced postpartum, while constant in controls. Athletes were not satisfied with advice related to strength training and nutrition during pregnancy.

Conclusion Elite athletes and active controls get pregnant easily, deliver healthy babies and decrease training during pregnancy and the first postpartum periods compared with prepregnancy. Most athletes and every third control returned to sport or exercise at week 0-6 postpartum. Athletes report stress fractures and increased BD and DT, but decreased ED postpartum. However, since relatively few athletes were included these findings need further investigation.

\section{INTRODUCTION}

Female elite athletes are competing well into their $30 \mathrm{~s},{ }^{1}$ and many wish to become pregnant and return to competitive sport after childbirth. Pregnant elite athletes compete in major events such as the Olympics. ${ }^{2}$ It has been stated that competitive athletes maintain a more strenuous training regimen than less active women throughout pregnancy, more

\section{What are the new findings?}

When comparing this sample of elite athletes with physically active controls, no differences in relation to fertility problems, miscarriage, preterm birth or low birth weight, were revealed.

- Both the elite athletes and controls decreased training volume in the first, second and third trimester as well as in the first two postpartum periods compared with prepregnancy, but more athletes than active controls returned to their sport or activity level within 6 weeks postpartum.

- Severe injuries (stress fractures) were only present among athletes in the postpartum period, and number of athletes with eating disorders was reduced (from prepregnancy and during pregnancy) at postpartum, while the number of controls with eating disorders was the same postpartum.

- Most athletes felt that their performance level was the same or better after becoming mothers, but neither athletes nor controls were satisfied with the guidance they received related to training.

quickly resume training postpartum ${ }^{2} 3$ and that giving birth results in a positive performance effect. ${ }^{4-7}$ However, studies suggest that elite pregnant athletes may encounter more potential risks of miscarriage, preterm birth, prolonged labour, lower fetal birth weight, ${ }^{8} 9$ pelvic floor dysfunctions, low back and pelvic girdle pain, than less active women. ${ }^{2} 10$ One recent example is a Norwegian cross-country skier. She trained during pregnancy, gave birth to a healthy baby, won four medals in the subsequent World Championship and became the most successful competitor of all time in the winter Olympics in February 2018. Unfortunately, she experienced two sacral stress fractures during postpartum. ${ }^{11}$

In the absence of medical or obstetrical contraindications, all pregnant women are encouraged to be physically active for at least a minimum of 150 min per week of moderateintensity aerobic activity. ${ }^{12}$ However, high-quality evidence for pregnant elite athletes is lacking, ${ }^{13}$ and there are no exercise 
guidelines specifically for these women, ${ }^{3}$ and the knowledge and 'recommendations' are mainly based on expert opinions or teammates. ${ }^{14}$

Due to the lack of specific evidence-based guidelines, a working group set out by the International Olympic Committee (IOC) collaborated with the aim to review the existing medical literature, resulting in five papers summarising the current evidence in this research field. ${ }^{38131516}$ However, very few of the existing studies included elite pregnant athletes, reflecting limited knowledge on the effect of participation in elite sport on the pregnant athlete, the fetus, and practical issues related to combining the role of being a mother and an elite athlete.

In sum, the knowledge is limited regarding elite athletes and fertility problems, miscarriage, preterm birth, common pregnancy problems, injuries, body image, eating disorders (ED) as well as training during pregnancy and return to training and competition in the postpartum period. Additionally, it is not known how pregnancy, birth and the postpartum period differ between elite athletes and physically active non-elite women. Finally, the experiences of the elite athlete themselves when it comes to practical guidance during pregnancy and the postpartum period are not known. Therefore, the aim of this study was to answer the following questions;

1. Do fertility problems, miscarriage, preterm birth or low birth weight differ between elite athletes and physically active non-elite women (controls)?

2. What is the training volume ( $\mathrm{min} /$ week) for elite athletes and controls during the three trimesters, and when do athletes and controls return to sport and exercise postpartum?

3. Do the experience of common complaints and complications differ between elite athletes and controls during pregnancy or delivery?

4. Do injuries, body dissatisfaction (BD), drive for thinness (DT) or ED differ between elite athletes as compared with controls during pregnancy or in the postpartum period?

5. Which practical challenges do elite athletes experience being pregnant and mothers?

\section{METHODS}

\section{Participants}

Athletes

The elite athletes were recruited by asking the sport directors/national team coaches for each national sport federation about names of those elite athletes who had been pregnant and given birth during the last 5 years. The elite athletes were asked if they themselves had or if they knew about teammates who had been pregnant and/or delivered during the defined study period. The inclusion criteria were being an elite athlete at international level (represented the national team, competed in the European or World Championship, World cup and or
Olympic Games and representing endurance sports, ballsports, aesthetic sports, weight class sports or technical sports), ${ }^{17}$ planning to return to the same competition level postpartum, age 25-40 years, a prepregnancy body mass index (BMI) $>18.5 \mathrm{~kg} / \mathrm{m}^{2}$ and $<26 \mathrm{~kg} / \mathrm{m}^{2}$ and be willing to fill out a questionnaire and/or participate in a structured interview within 1 year postpartum (of the last baby). Exclusion criteria were if the athlete did not fill out the questionnaire or answered questions in the structured interview satisfactorily (such as lack of information regarding training and/or birth weight), or if she did not plan to compete at international level postpartum. Eligible to this cross-sectional study was the total population of Norwegian female elite athletes who were pregnant and gave birth during the data collection period (2015-2018, $\mathrm{n}=41)$. Of the 41 athletes recruited, one did not have time to participate, 5 were excluded due to the fact that they did not plan to compete at an international level postpartum and one did not respond for unknown reason.

\section{Physically active non-elite controls}

The inclusion criteria were being regularly physically active ( $>150$ min per week) for at least 2 years prepregnancy, not having participated in competitive sports at national or international level the last 5 years, age 25-40 years, a prepregnancy BMI $>18.5 \mathrm{~kg} / \mathrm{m}^{2}$ and $<26 \mathrm{~kg} / \mathrm{m}^{2}$ and be willing to fill out a questionnaire and/or participate in a structured interview within 1 year postpartum (of the last baby). The participants were recruited from healthcare centres, general practitioners and obstetricians in Norway. Exclusion criteria were if the control did not fill out the questionnaire or answered questions in the structured interview satisfactory (such as lack of information regarding training and/or birth weight), competing at the elite (national or international) level or if she did not plan to do regular exercise postpartum.

Of the 84 women recruited for the control group, 27 were excluded due to the following reasons: age $>40$ years $(\mathrm{n}=2), \mathrm{BMI}>26 \mathrm{~kg} / \mathrm{m}^{2}(\mathrm{n}=8),<150 \mathrm{~min}$ of physical activity per week prepregnancy $(n=14)$, competed in sport at national level (not elite) during the last 5 years $(n=1)$, delivered incomplete questionnaires and not willing to answer the missing questions by a telephone interview $(n=2)$.

\section{Ethics}

The project was reviewed by the Regional Committee for Medical and Health Research Ethics (2015/1888/REK), who concluded that, according to the Act on medical and health research (the Health Research Act 2008), the study did not require full review by REK. The project was approved by the Norwegian Social Science Data Service (NSD 44723). In accordance with the Declaration of Helsinki, all participants received written information about the project's purpose and procedures and gave consent to participate. 


\section{Assessment methods and procedures}

\section{Questionnaire}

Since no standardised questionnaires aiming to assess elite athletes and pregnancy-related questions as well as training during pregnancy and return to training in the postpartum period exist, the authors developed such a questionnaire. Topics such as training ( $\mathrm{min} /$ week) and competitive history, fertility and miscarriage (ie, spontaneous abortion or pregnancy loss during the first 20 weeks of the pregnancy), common problems and complications during pregnancy and delivery, injuries, BD, DT, ED (prior to or during pregnancy and during the postpartum period) and practical experiences related to being a mother were included. Training volume and physical activity was divided into three main periods: prepregnancy (average for the last year prior to pregnancy), pregnancy (first, second and third trimester) and postpartum (0-3, 3-6 and 6-9 months postpartum). Athletes and controls were also asked for training intensity during pregnancy and postpartum. However, few of the athletes reported data on intensity of god quality and therefore these data are not included in the analyses or result chapter. Having a fertility problem was defined as having tried to get pregnant for $>12$ months. ${ }^{18}$ Low birth weight and high birth weight were defined as $<2500 \mathrm{~g}$ and $>4000 \mathrm{~g}$, respectively. ${ }^{19}$ Athletes and controls selfreported whether they felt a change in performance level from prepregnancy (the last 6 months non-pregnant period) to $3-9$ month postpartum by selecting one of the following response-options: 'better', 'similar to', 'decreased' or 'I do not know'. Athletes and controls were asked whether they were satisfied or not with the advice they received from their performance team (coaches, physical therapists, doctors and nutritionists) or healthcare personnel and fitness instructors during pregnancy. Finally, the athletes were asked about their experiences related to return to their sport. Participants filled out the questionnaire (or answered the questionnaire through a telephone interview) at a mean of 4 months after delivery (range 1-9 months) for athletes and a mean of 5 months (range 1-8 months) for controls.

\section{The Eating Disorder Inventory}

To assess BD and DT, two subtests from the Eating Disorder Inventory (EDI-3) ${ }^{20}$ were used. Participants were asked to fill out the EDI-subtests and imagine how they felt prepregnancy (the last 6 months non-pregnant period) and then how they felt at the time when they filled out the questionnaire (mean 4 months after delivery (range 1-9 months)). Participants were classified as 'at risk' for ED if they met at least one of the following criteria: EDI-DT score $\geq 15$, EDI-BD score $\geq 14$ or a positive answer to the question asking for present (1-9 months postpartum) or previous (the last 6 months non-pregnant period) ED. ${ }^{17}$

\section{Structured telephone interviews}

Five athletes and four controls did not have the time to fill out the questionnaire and were interviewed by telephone using the same questions as in the original questionnaire at postpartum. In addition, two of the authors (the first and second authors) contacted all athletes and controls for a short telephone interview, to collect the extra information regarding questions related to the postpartum period (at 9 months postpartum) that they were not able to answer at the first data collection period. In addition, we were then able to optimise the answers that were not fully answered in the questionnaire (ie, baby's birth weight). The two interviewers are both well trained in doing interviews and followed the same procedures regarding how to ask the questions and how to include follow-up questions.

\section{Eating Disorder Examination}

ED were determined using the clinical interview Eating Disorder Examination (EDE).$^{21}$ The EDE assesses ED psychopathology and key ED behaviours. It consists of four subscales and items are scored on a seven-point Likert scale with higher scores representing greater severity of psychopathology. ${ }^{21}$ All athletes $(n=6)$ and controls $(n=7)$ who met one or more of the criteria for being 'at risk' for ED based on the questionnaire were asked to participate in a telephone-based EDE interview. The EDE interviews were performed by an ED expert with many years of experience related to the EDE interview. To test for possible false negatives (incorrectly classified as not 'at risk'), five athletes and five controls with no indication of disordered eating behaviour were asked to participate in the telephone-based EDE interview 3-9 months postpartum. For being diagnosed with an ED, the diagnostic and statistical manual (DSM)-5 criteria for anorexia nervosa, bulimia nervosa or other specified feeding or eating disorder (OSFED) had to be met. ${ }^{22}$

\section{Participant involvement and piloting of the questionnaire}

Two former elite athletes who had experienced being pregnant, mothers and elite athletes at the same time were invited to the first project meeting to discuss the research questions with the author group. These two also participated in the development of the questionnaire and interview guide. To test the questionnaire two other athletes at national level and who had given birth prior to the data collection period filled out the questionnaire and responded with comments to the questions included. Based on their comments, three of the questions (regarding guiding of training, return to play and training history) were revised.

\section{Statistical analysis}

Statistical analyses were performed using Statistical Package of Social Sciences (SPSS) V.24 (IBM, Armonk, New York, USA). Between-group differences (athletes versus controls) were examined using two-tailed independent samples T-tests or $\chi^{2}$ tests (two-sided Fisher's exact test). Data are presented as number and percentage or mean and SD. Within-group changes in BD and DT were examined with paired-samples T-tests prepregnancy 
Table 1 Sample characteristics

\begin{tabular}{|c|c|c|c|c|c|c|}
\hline & \multicolumn{4}{|c|}{ Athletes $(n=34)$} & $\begin{array}{l}\text { Controls } \\
(n=34)\end{array}$ & $P$ value \\
\hline Age, mean (SD) & \multicolumn{4}{|c|}{$33.1(3.9)$} & $31.5(3.5)$ & 0.07 \\
\hline BMI prepregnancy, mean (SD) & \multicolumn{4}{|c|}{$21.6(1.7)$} & $22.4(1.7)$ & $0.05^{\star}$ \\
\hline Higher education, n (\%) & \multicolumn{4}{|c|}{$28(82)$} & $29(85)$ & 1.00 \\
\hline Married, n (\%) & \multicolumn{4}{|c|}{$18(53)$} & $14(41)$ & 0.47 \\
\hline Cohabitant, n (\%) & \multicolumn{4}{|c|}{$16(47)$} & $18(53)$ & 0.81 \\
\hline Performance level & Gold & Silver & Bronze & Total & & \\
\hline Olympic Games & 26 & 4 & 6 & 36 & & \\
\hline World Championships & 53 & 26 & 15 & 94 & & \\
\hline $\begin{array}{l}\text { Eur. Championships/ } \\
\text { Champions league }\end{array}$ & 40 & 6 & 1 & 47 & & \\
\hline World Cup victories & 115 & & & 115 & & \\
\hline National Champions & & & & 104 & & \\
\hline Total number of medals in inter & ompetit & & & 292 & & \\
\hline
\end{tabular}

Data presented as number (percentages) or mean (SD). Performance level is presented as number of medals for the athletic group.

*Significant difference between groups with $p \leq 0.05$.

versus postpartum. Repeated measures analysis of variance with Greenhouse-Geisser correction and Bonferroni posthoc test was used to look at differences in training volume between time periods. Results are presented as mean differences. Figures are presented with mean and $95 \%$ CI. P $\leq 0.05$ was considered statistically significant.

\section{RESULTS}

\section{Subject characteristics}

The athletes and controls had similar mean age (table 1 ).

Overall, the athletes had 36 medals (gold, silver or bronze) in the Olympics and 208 victories in European and World Championships or World Cups (table 1). Among the controls, $79 \%$ reported being involved in organised sports during their youth. Except for six (18\%) and four (12\%) multiparous athletes and controls, respectively, the rest were a first live third trimester birth. The average weight gain during pregnancy did not differ between elite athletes and controls (mean (SD): $12.3 \mathrm{~kg}$ $(4.1 \mathrm{~kg})$ vs $13.3 \mathrm{~kg}(3.4 \mathrm{~kg}), \mathrm{p}=0.28)$.

\section{Endurance training}

Athletes had higher mean endurance training volume than controls at every measurement period $(p<0.001)$ (figure 1). In addition, endurance training volume differed between time points in the athletic group $(\mathrm{F}(3.9,128.5)=21.2, \quad \mathrm{p}<0.001)$ and the control group $(\mathrm{F}(3.1,102.4)=11.7, \mathrm{p}<0.001)$, respectively. Both groups showed a decrease from prepregnancy to the first and third trimester $(\mathrm{p}<0.001), 0-3$ months postpartum $(\mathrm{p}<0.001)$ and $3-6$ months postpartum (athletes: $\mathrm{p}=0.04$, controls: $\mathrm{p}=0.01$ ). During pregnancy, endurance training was higher in second trimester than in first for both groups (athletes: $\mathrm{p}<0.001$, controls: $\mathrm{p}=0.03$ ) and also higher than third for the athletes $(\mathrm{p}<0.001)$. In the postpartum period, endurance training increased from
0-3 months to 3-6 months (athletes: $\mathrm{p}<0.001$, controls $\mathrm{p}=0.02$ ) and 6-9 months (athletes: $\mathrm{p}<0.001$, controls: $\mathrm{p}<0.01)$ in both groups. None of the athletes or controls included high intensity endurance training during the second or third trimester of pregnancy. Three athletes reported 1-2 training sessions with high intensity during the first trimester.

\section{Strength training}

Mean strength training volume also differed between athletes and controls at all time points $(\mathrm{p}<0.001)$ (figure 2) and between time points within the athletic $(\mathrm{F}(2.6,86.4)=54.1, \mathrm{p}<0.001)$ and the control group $(\mathrm{F}(3.2,105.7)=5.9, \mathrm{p}=0.001)$, respectively. The athletes showed a decrease from prepregnancy to first to third trimester and $0-3$ months postpartum $(\mathrm{p}<0.001)$. During

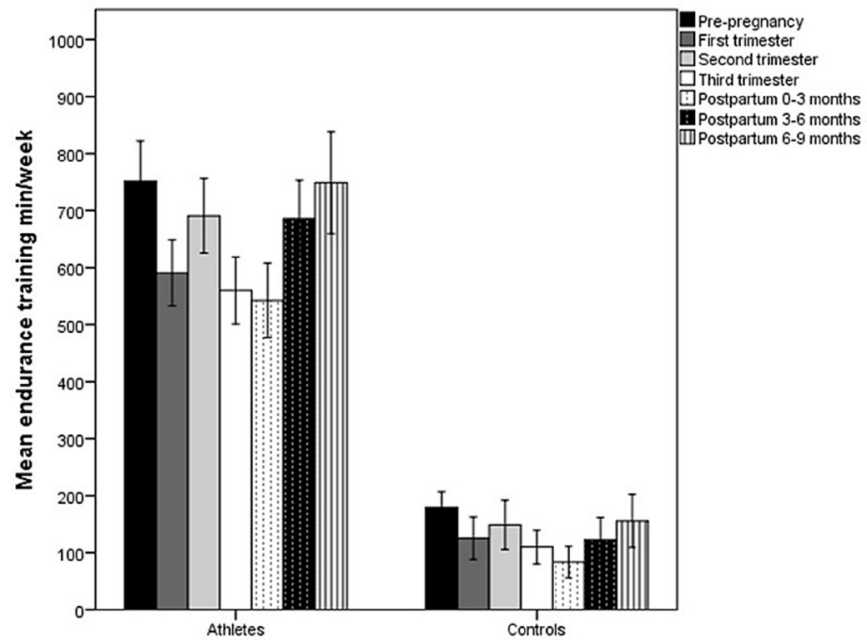

Figure 1 Mean $(95 \% \mathrm{Cl})$ minutes per week spent on endurance training prepregnancy, during pregnancy and postpartum in athletes and controls. 


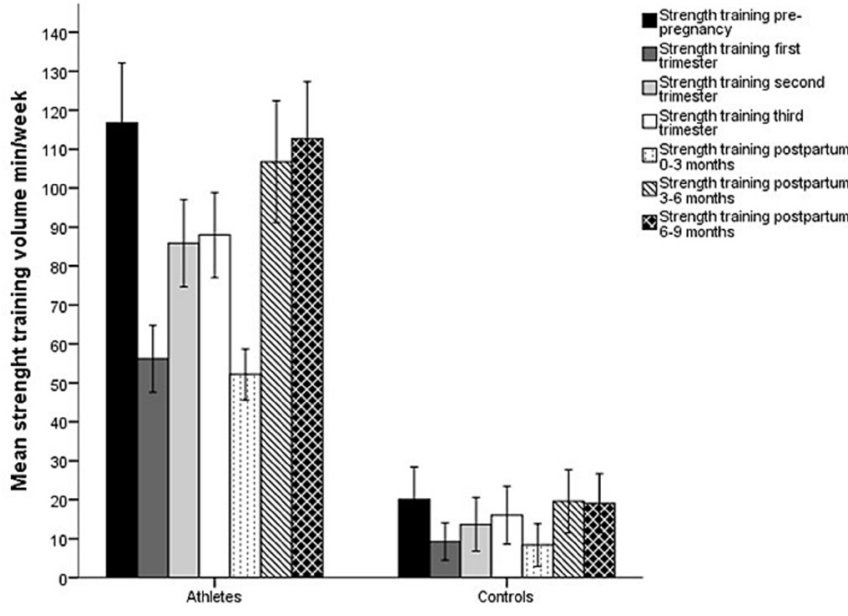

Figure 2 Mean $(95 \% \mathrm{Cl})$ minutes per week spent on strength training prepregnancy, during pregnancy and postpartum in athletes and controls.

pregnancy, strength training volume was lower in first trimester compared with second and third $(\mathrm{p}<0.001)$. The training volume further decreased from third trimester to 0-3 months postpartum and increased from $0-3$ to $3-6$ and $6-9$ months postpartum $(\mathrm{p}<0.001$ for all time points). In the control group, only strength training volume in first trimester was lower than prepregnancy, 3-6 months postpartum and 6-9 months postpartum ( $\mathrm{p}=0.04, \mathrm{p}=0.04, \mathrm{p}=0.03$, respectively).

\section{Total training volume}

Total training volume (combined minutes of endurance and strength training per week) also differed between athletes and controls at every time point $(p<0.001)$ and between the different time points within the athletic group $(\mathrm{F}(4.0,131.6)=32.5, \mathrm{p}<0.001)$ and the control group $(\mathrm{F}(3.2,105.1)=13.5, \mathrm{p}<0.001)$, respectively. Within both groups, prepregnancy training volume was significantly higher than the other time points, except 6-9 months postpartum. During pregnancy, both groups differed between first and second trimester (athletes: $\mathrm{p}<0.001$, controls: $\mathrm{p}=0.02$ ) and the athletic group also differed between second and third trimester $(\mathrm{p}<0.001)$. In the postpartum period, total training volume increased from 0-3 to 3-6 (athletes: $\mathrm{p}<0.001$, controls: $\mathrm{p}<0.01$ ) and 6-9 months (athletes: $\mathrm{p}<0.001$, controls: $\mathrm{p}=0.001$ ) in both groups.

Most athletes $(71 \%)$ and $32 \%$ of the controls returned to their sport and exercise routines at week 0-6 postpartum $(\mathrm{p}=0.002)$. A similar frequency of athletes $(24 \%)$ and controls (24\%) returned to sport and exercise at 7-12 weeks postpartum $(\mathrm{p}=1.000)$. A higher frequency of controls $(41 \%)$ as compared with athletes $(6 \%)$ returned to their routines at week 13-18 $(\mathrm{p}=0.001)$.

\section{Concerns and outcomes related to pregnancy and birth}

None of the athletes and one control reported having fertility problems. Two athletes reported in vitro fertilisation. These two athletes were both homosexual. The average birth weight for the babies was within normal range for both groups of offspring and no differences between groups were observed. Eight and 11 babies from athlete and control mothers, respectively, had high birth weight $(p=0.59)$. When controlled for multiparity, one baby from each group had low birth weight (table 2).

\section{Complaints and complications during pregnancy}

No difference in general urinary incontinence in the postpartum period was observed between athletes and controls ( $21 \%$ vs $27 \%$, p=0.78). Self-reported complaints are reported below (table 3 ).

\section{Injuries}

Four (12\%) athletes reported acute training-induced injuries during pregnancy (two muscle strains, one fracture and one ankle distortion), and all occurred in the third trimester. In addition, four (12\%) athletes experienced five stress fractures during the postpartum period (three in the sacrum, one in the fifth metatarsal and one in tibia). None of the participants in the control group reported acute or overuse training-induced injuries during pregnancy or within the first 9 months postpartum. Two of the four athletes with stress fractures represented endurance type sports and two represented team ball sports. They all returned to high volume sport specific training within 6 weeks postpartum, and they

Table 2 Self-reported concerns and outcomes related to pregnancy and delivery

\begin{tabular}{|c|c|c|c|}
\hline & Athletes $(n=28)$ & Controls $(n=29)$ & $P$ value \\
\hline In vitro fertilisation, $\mathrm{n}(\%)^{*}$ & $2(6)$ & & \\
\hline Miscarriage, $\mathrm{n}(\%) \dagger$ & $3(11)$ & $8(28)$ & 0.18 \\
\hline Preterm birth, n (\%) & $2(7)$ & $1(3)$ & \\
\hline Caesarean, n (\%) & $1(4)$ & $2(7)$ & \\
\hline Birth weight baby $(\mathrm{g})$, mean (SD) & $3607.1(544.7)$ & $3587.3(610.1)$ & 0.90 \\
\hline Apgar score (5 min), mean (SD) & $9.0(0.7)$ & $9.0(0.7)$ & 0.72 \\
\hline
\end{tabular}

Data presented as number (percentages) or mean (SD). Multiparous athletes $(n=6)$, multiparous controls $(n=4)$ and one control with missing value on parity are excluded from the analyses.

${ }^{*}$ A total of 34 athletes included. One insemination, one insemination with donor.

†Spontaneous abortion or pregnancy loss during the first 20 weeks of pregnancy. Three controls had two miscarriages each. 
Table 3 Self-reported complaints during the three trimesters in pregnancy for both athletes $(n=34)$ and controls $(n=34)$

\begin{tabular}{|c|c|c|c|c|c|c|}
\hline & \multicolumn{2}{|c|}{ First trimester } & \multicolumn{2}{|c|}{ Second trimester } & \multicolumn{2}{|c|}{ Third trimester } \\
\hline & Athletes & Controls & Athletes & Controls & Athletes & Controls \\
\hline Nausea, n (\%) & $21(62)$ & $28(82)$ & $5(15)^{\star \star}$ & $16(47)$ & $2(6)$ & $3(9)$ \\
\hline Fatigue, n (\%) & $29(85)^{\star \star \star}$ & $13(38)$ & $14(41)$ & $11(32)$ & $7(21)$ & $6(18)$ \\
\hline Musculoskeletal complaints (pelvic), n (\%) & $1(3)$ & - & $3(9)$ & $3(9)$ & $3(9)$ & $5(15)$ \\
\hline $\begin{array}{l}\text { Musculoskeletal complaints } \\
\text { (low back pain), n (\%) }\end{array}$ & - & $4(12)$ & $4(12)$ & $7(21)$ & $4(12)^{\star}$ & $13(38)$ \\
\hline Contractions, n (\%) & $1(3)$ & $1(3)$ & $8(24)$ & $3(9)$ & $9(27)$ & $6(18)$ \\
\hline Obstipation, n (\%) & $5(15)$ & $9(26)$ & $6(18)$ & $12(35)$ & $5(15)^{\star}$ & $15(44)$ \\
\hline Depression, n (\%) & $2(6)$ & - & $2(6)$ & $2(6)$ & $1(3)$ & $4(12)$ \\
\hline Anxiety, n (\%) & $1(3)$ & $1(3)$ & - & $1(3)$ & - & $3(9)$ \\
\hline
\end{tabular}

Data presented as number (percentages).

${ }^{*}$ Athletes significantly different from controls $(p \leq 0.05)$.

${ }^{* *}$ Athletes significantly different from controls $(p \leq 0.01)$.

${ }^{* * *}$ Athletes significantly different from controls $(p \leq 0.001)$.

were all breastfeeding and two had a history of ED (but did not meet the DSM-5 criteria postpartum).

\section{Body dissatisfaction, drive for thinness, and eating disorders}

As a group, neither athletes nor controls had average BD or DT scores above cut-off prepregnancy or in the postpartum period (figure 3 ).

As a group, athletes increased both $\mathrm{BD}$ and DT scores, while controls decreased their DT score from prepregnancy to postpartum. Six athletes $(18 \%)$ and seven controls $(21 \%)$ reported high scores on both BD and DT postpartum. Questionnaire data indicated that nine athletes (26\%) and four controls (12\%) experienced challenges related to prior or current ED $(p=0.13)$. Four $(12 \%)$ athletes and one $(3 \%)$ control also reported having an ED prior to or during pregnancy. At postpartum, two

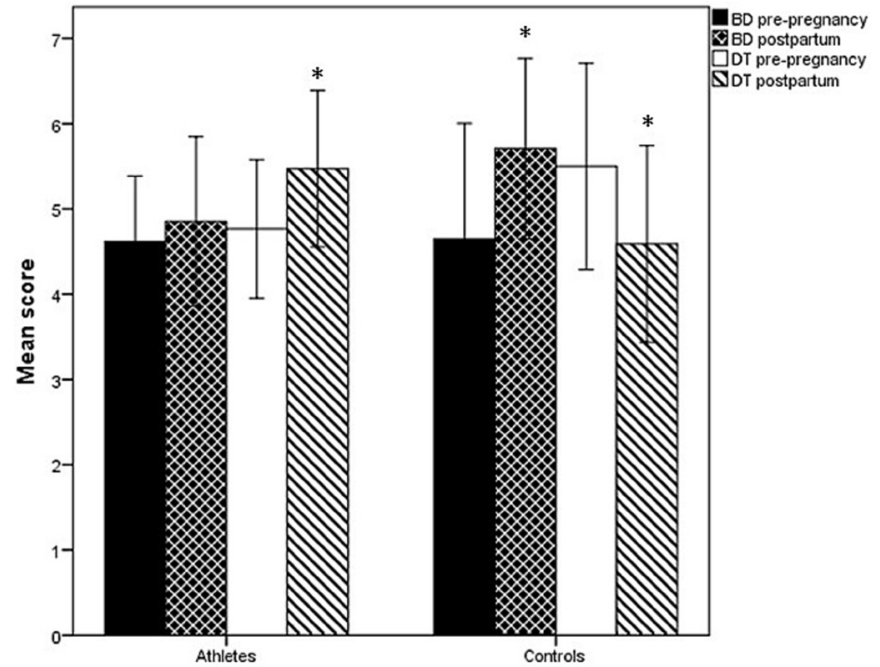

Figure 3 Mean $(95 \% \mathrm{Cl})$ score on BD and DT prepregnancy and postpartum in athletes and controls. *Significant $(\leq 0.05)$ within-group change from prepregnancy to postpartum. BD, body dissatisfaction; DT, drive for thinness. of the six 'at risk' athletes met the DSM- 5 criteria for bulimia nervosa and one for OSFED. Among the 'at risk' controls, one met the DSM- 5 criteria for bulimia nervosa postpartum. None of the athletes or controls with 'no risk' met the DSM-5 criteria for ED.

\section{Performance level}

Most athletes reported that their performance level was the same $(n=15,44 \%)$ or better $(n=5,15 \%)$ in the postpartum period at 3-9 months (mean 4 months after delivery) compared with the last 6 months non-pregnant period, while $26 \% \quad(n=9)$ reported an experienced decrease in performance level and $15 \%(n=5)$ did not know.

Most controls reported that their exercise performance was the same $(\mathrm{n}=28,82 \%)$ while two $(6 \%)$ and four $(12 \%)$ reported better and decreased exercise performance.

\section{Practical experience for athletes}

Six $(18 \%)$ and $14(41 \%)$ athletes were satisfied with the advice related to nutrient intake and training, respectively, during pregnancy. For controls, few responded to the nutrition question, but 16 out of 21 were not satisfied with the advices related to training. Eighteen (53\%) athletes and 14 (out of the 21 controls who answered this question) reported being specifically uncertain about strength training. Four (12\%) athletes were recommended not to breastfeed and did therefore not breastfeed at all. The other $30(88 \%)$ athletes were breastfeeding and $87 \%$ of those were planning to breastfeed for a longer period than 6 months. All controls, except for one, were breastfeeding and planning to do for more than 6 months.

A similar percentage of athletes as compared with controls reported that they did not get enough sleep to recover properly $(29(85 \%)$ vs $26(76 \%), \mathrm{p}=0.54)$. Most athletes preferred not to bring their baby to training $(\mathrm{n}=22,65 \%)$ or competition $(\mathrm{n}=24,71 \%)$. In 
an open-ended question to the athletes, the two most frequent reported success factors (to perform at high level postpartum) was time to recovery (reported by $\mathrm{n}=25,74 \%)$ and having the 'right' partner $(\mathrm{n}=21,62 \%)$.

\section{DISCUSSION}

It should be noted that the athletes in our study were at a very high-performance level, achieving 292 medals in international competitions and as many as 36 medals in the Olympic Games. Based on the concerns raised in the literature regarding potential adverse risks of maternal exercise on the developing fetus, labour and birth outcomes $^{89}$ and questions asked by athletes and their support team, it is interesting to note that fertility problems, miscarries, preterm birth and low birth weight seem not to be more common in our sample of elite athletes compared with physically active controls. These findings might support the suggestions made by the IOC working group that low to moderate intensity exercise does not seem to increase the risk of miscarriage or preterm birth, and that exercise reduces the risk of excess birth weight without boosting the risk of low birth weight. ${ }^{8}$

Despite these findings, some studies have questioned the risk of complications related to obstetrical outcomes in women with high exercise volume. ${ }^{2324}$ The IOC working group and others suggested that physical activity during pregnancy may reduce the need for C-section. ${ }^{89}$ These suggestions are in line with findings in the present study. However, since relatively few athletes were included in our study, these findings need to be further investigated.

Taken together, it is tempting to argue that it seems to be safe to continue with the reported level and variation in training volume during pregnancy for this group of highly trained elite athletes representing different sports. One should keep in mind, that based on a small study on highly endurance trained elite athletes we have previously reported that exercise at intensity above $90 \%$ of maternal maximal heart rate possibly comprise fetal well-being. ${ }^{25-27}$ This might also explain why none of the athletes or controls reported high intensity training during the second and third trimester.

As expected, the athletes had a much higher training volume compared with the controls, but it is interesting to note that the training pattern throughout both pregnancy and the postpartum period was identical comparing the two groups. Both athletes and controls decreased their training volume in the first, second and third trimester compared with prepregnancy levels, as also shown in previous studies. ${ }^{28}{ }^{29}$ The reasons for this may be commonly reported complaints during these periods, such as nausea and fatigue in the first trimester and musculoskeletal complaints and constipation in the third trimester. ${ }^{30-32}$ These are all commonly reported by both athletes and controls in this study. The observed progressive increase in training volume in the postpartum period is in line with guidelines. ${ }^{1633}$
We might hypothesise that the significant reduction in strength training in the first trimester for both groups is due to the reasons mentioned above. In addition, neither athletes nor controls were satisfied with the advice in relation to strength training and they might have been more restrictive due to the uncertainty of possible consequences to the fetus. The finding that also controls were dissatisfied with the advices related to exercise are in line with other studies both in Norway ${ }^{34}$ and internationally. ${ }^{29}$ Interestingly, in partly contrast to previous suggestions that elite athletes experience an increase in performance level, ${ }^{4-7}$ most of the athletes in this study reported the performance level to be similar to or better than prepregnancy, while more than one out of four athletes reported that their performance was reduced compared with prepregnancy level.

Although acute injuries were not found to be a problem among athletes or controls during pregnancy or postpartum, it is important to note that as many as four athletes reported stress fractures during the postpartum period. These fractures might be related to a number of reasons, such as a sudden increase in training load early postpartum, insufficient strength training during pregnancy and early postpartum, history of relative energy deficiency in sport (RED-s) or ED (reported by two of these four athletes) and/or possible inadequate intake of calcium and vitamin $\mathrm{D}^{35}$ during pregnancy and the breastfeeding period. Only one in three athletes were recommended to increase the calcium-intake and vitamin D-intake during pregnancy and postpartum (data not shown). This might indicate that an increased focus on bone enhancing strategies such as optimal energy-intake, calcium-intake and vitamin D-intake as well as strength training and weight bearing exercise during the lactation period is of utmost importance, especially among elite athletes.

It is interesting to note that despite reported disorded eating (DE) prevalence between $0.6 \%$ and $27.8 \%$ among pregnant women in general, ${ }^{36}$ in our study, neither athletes nor controls (as a group) had average BD or DT scores above cut-off prepregnancy or postpartum. The finding related to the increased DT score for the athletes (and not for the controls) postpartum might be explained by the fact that these athletes were eager to achieve their prepregnancy shape and fitness (ideal body composition) as fast as possible to optimise performance.

It was also an important finding that the number of athletes who met the criteria for ED were lower postpartum compared with prepregnancy and pregnancy. This might indicate that pregnancy per se does not trigger or increase the possibility for maintenance of an ED for elite athletes as indicated in non-athletic women. ${ }^{36}$

Regarding complaints related to the advices during pregnancy and postpartum, it is of important concern that as many as four athletes were recommended (by two coaches and two physiotherapists) not to breastfeed for no other reason than possible impaired performance. In addition, the limited advice related to energy-intake 
and nutrient-intake and strength training indicate both the fact that the athletes were not supervised well and a research gap in these factors. Finally, it is important to take into account the athletes' own experiences concerning lack of time for recovery, as well as practical challenging situations such as bringing the baby to training and competition.

\section{Strengths and limitations}

This is the first study to investigate a large number of pregnancy-related and postpartum-related variables in athletes at a very high-performance level compared with controls. Other strengths are the pilot-testing of the questionnaire and the use of a combination of questionnaire and interview that allowed us to add and/or correct nonreporting or possible miss-reporting in the self-reported questionnaire. Finally, valid outcome measures such as clinical interview for ED diagnosis was used.

Limitations of this study include a relatively small sample size and the risk of type 2 statistical errors. Regarding the sample size, this is the total population of highly elite athletes who was pregnant and gave birth during the data collection period. However, we are aware of the fact that the very elite athletes who had experienced problems with fertility and or miscarriage might not have been recruited to this study. None of the five participants excluded since they did not continue at international level reported experienced fertility problems or miscarriage. A retrospective design increases the risk for recall bias and thereby under/over-reporting. It is also important to take into consideration that the athletes' responses might be affected by desirability bias and therefore under-reported complaints or complications and/or under/over-reported training volume in the different periods. Also, 'remembering wrong' regarding training volume, birth complications and when they started exercising postpartum might have influenced the results. However, most of the elite athletes used training diary during the study period (also) and these biases should therefore be minimalised. Finally, data regarding training intensity were not reported detailed enough and was of too poor quality to be included in the analysis.

\section{CONCLUSIONS}

Findings from this sample of elite athletes indicate that fertility problems, miscarriage, preterm birth and low birth weight are not more frequent in elite athletes than physically active controls. Both groups decreased their training volume in the trimesters and in the first two periods postpartum compared with prepregnancy. Almost three out of four athletes and one out of three controls returned to their sport and exercise routines at week 0-6 postpartum.

Athletes reported fewer complaints than controls during pregnancy but they only reported severe injuries such as stress fractures. The number of athletes with ED was reduced, while the number of controls with ED was the same at postpartum.
Most athletes felt that their performance level was the same or better after becoming mothers, and none of the groups were satisfied with the training/exercise advice and the most important practical challenge was having enough time for recovery.

Contributors This study is a multidisciplinary cooperation between experts in exercise medicine from the Norwegian School of Sport Sciences and the University of Agder. JS-B generated the original research idea, in collaboration with MKT, GM, CS-B and NS. JS-B, GM, MKT and CS-B developed the questionnaire package and CS-B recruited participants. CS-B and NS were responsible for the statistical analyses and JS-B for the interviews. JS-B wrote the main manuscript with assistance from all the other authors. All authors have approved the final manuscript.

Funding The authors have not declared a specific grant for this research from any funding agency in the public, commercial or not-for-profit sectors.

Competing interests None declared.

Patient consent for publication Not required.

Provenance and peer review Not commissioned; externally peer reviewed.

Data availability statement Data are available on reasonable request.

Open access This is an open access article distributed in accordance with the Creative Commons Attribution Non Commercial (CC BY-NC 4.0) license, which permits others to distribute, remix, adapt, build upon this work non-commercially, and license their derivative works on different terms, provided the original work is properly cited, appropriate credit is given, any changes made indicated, and the use is non-commercial. See: http://creativecommons.org/licenses/by-nc/4.0/.

\section{ORCID iDs}

Jorunn Sundgot-Borgen http://orcid.org/0000-0002-5291-5486

Christine Sundgot-Borgen https://orcid.org/0000-0002-1149-0442

Grethe Myklebust https://orcid.org/0000-0002-0692-7494

Nina Sølvberg http://orcid.org/0000-0002-6334-9811

Monica Klungland Torstveit https://orcid.org/0000-0003-2798-9675

\section{REFERENCES}

1 Elmenshawy AR, Machin DR, Tanaka H. A rise in peak performance age in female athletes. Age 2015;37:57

2 Erdener U, Budgett R. Exercise and pregnancy: focus on advice for the competitive and elite athlete. Br J Sports Med 2016;50:567.

3 Bo K, Artal R, Barakat R, et al. Exercise and pregnancy in recreational and elite athletes: 2016 evidence summary from the IOC expert group meeting, Lausanne. Part 1-exercise in women planning pregnancy and those who are pregnant. Br J Sports Med 2016;50:571-89.

4 The Guardian International web page. Does childbirth improve athletic ability? London, United Kingdom. Available: https://www. theguardian.com/lifeandstyle/the-running-blog/2014/nov/04/doeschildbirth-improve-athletic-ability [Accessed 29 Jan 2019].

5 ABC NEWS web page. Serena Williams: can having a baby actually improve athletic performance in the long run? Australia. Available: https://www.abc.net.au/news/2018-09-07/serena-williams-whysome-athletes-stronger-after-pregnancy/10208896 [Accessed 29 Jan 2019].

6 Telegraph. Jessica Ennis-Hill's pregnancy may lead to enhanced performance in the Run-up to Rio 2016. United Kingdom. Available: https://www.telegraph.co.uk/sport/othersports/athletics/ 10563263/Jessica-Ennis-Hills-pregnancy-may-lead-to-enhancedperformance-in-the-run-up-to-Rio-2016.html [Accessed 29 Jan 2019].

7 Zaharieva E. Olympic participation by women. Effects on pregnancy and childbirth. JAMA 1972;221:992-5.

8 Bo K, Artal R, Barakat R, et al. Exercise and pregnancy in recreational and elite athletes: 2016 evidence summary from the IOC expert group meeting, Lausanne. Part 2-the effect of exercise on the fetus, labour and birth. Br J Sports Med 2016;50:1297-305.

9 Bisson M, Croteau J, Guinhouya BC, et al. Physical activity during pregnancy and infant's birth weight: results from the 3D Birth Cohort. BMJ Open Sport Exerc Med 2017;3:e000242.

10 Kruger JA, Dietz HP, Murphy BA. Pelvic floor function in elite nulliparous athletes. Ultrasound Obstet Gynecol 2007;30:81-5. 
11 Solli GS, Sandbakk Øyvind, Ø S. Training characteristics during pregnancy and postpartum in the world's most successful cross country skier. Front Physiol 2018;9:595.

12 American College of obstetricians and Gynecologists. physical activity and exercise during pregnancy and the postpartum period. Committee opinion no. 650. Obstet Gynecol 2015;126:e135-42.

13 Bo K, Artal R, Barakat R, et al. Exercise and pregnancy in recreational and elite athletes: 2016/2017 evidence summary from the IOC expert group meeting, Lausanne. Part 5. recommendations for health professionals and active women. Br J Sports Med 2018;52:1080-5.

14 Tenforde AS, Toth KES, Langen E, et al. Running habits of competitive runners during pregnancy and breastfeeding. Sports Health 2015;7:172-6.

15 Bo K, Artal R, Barakat R, et al. Exercise and pregnancy in recreational and elite athletes: 2016/17 evidence summary from the IOC expert group meeting, Lausanne. Part 4Recommendations for future research. Br J Sports Med 2017:51:1724-6.

16 Bo K, Artal R, Barakat R, et al. Exercise and pregnancy in recreational and elite athletes: 2016/17 evidence summary from the IOC expert group meeting, Lausanne. Part 3-exercise in the postpartum period. Br J Sports Med 2017;51:1516-25.

17 Torstveit MK, Sundgot-Borgen J. The female athlete triad: are elite athletes at increased risk? Med Sci Sports Exerc 2005;37:184-93.

18 WHO. International classification of diseases (ICD 10), 2016. Available: https://icd.who.int/browse10/2016/en\#/N97

19 Wiebe HW, Boulé NG, Chari R, et al. The effect of supervised prenatal exercise on fetal growth. Obstetrics \& Gynecology 2015;125:1185-94.

20 Garner DM. EDI-3 eating disorder Inventory-3 professional manual. Odessa, Florida: Psychological Assessment Resources. Inc, 2004.

21 Fairburn CG, Beglin SJ. Cognitive behavior therapy and eating disorders. In: Fairburn CG, ed. New York: Guilford Press, 2008: 309-13.

22 American Psychological Association (APA). Diagnostic and statistical manual of mental disorders (DSM-5): American psychiatric PUB 2013.
23 Hjollund $\mathrm{NHI}$, Jensen TK, Bonde JPE, et al. Spontaneous abortion and physical strain around implantation: a follow-up study of firstpregnancy planners. Epidemiology 2000;11:18-23.

24 Madsen M, Jørgensen T, Jensen ML, et al. Leisure time physical exercise during pregnancy and the risk of miscarriage: a study within the Danish national birth cohort. BJOG 2007;114:1419-26.

25 Morrow RJ, Knox Ritchie JW, Bull SB. Fetal and maternal hemodynamic responses to exercise in pregnancy assessed by Doppler ultrasonography. Am J Obstet Gynecol 1989;160:138-40.

26 Salvesen Kjell Å, Hem E, Sundgot-Borgen J. Fetal wellbeing may be compromised during strenuous exercise among pregnant elite athletes. Br J Sports Med 2012;46:279-83.

27 Szymanski LM, Satin AJ. Strenuous exercise during pregnancy: is there a limit? Am J Obstet Gynecol 2012;207:179.e1-6.

28 Gjestland K, Bø K, Owe KM, et al. Do pregnant women follow exercise guidelines? prevalence data among 3482 women, and prediction of low-back pain, pelvic girdle pain and depression. $\mathrm{Br} J$ Sports Med 2013;47:515-20.

29 Nascimento SL, Surita FG, Godoy AC, et al. Physical activity patterns and factors related to exercise during pregnancy: a cross sectional study. PLoS One 2015;10:e0128953.

30 Jarvis S, Nelson-Piercy C. Management of nausea and vomiting in pregnancy. BMJ 2011;342:d3606.

31 Bialobok KM, Monga M. Fatigue and work in pregnancy. Curr Opin Obstet Gynecol 2000;12:497-500.

32 Casagrande D, Gugala Z, Clark SM, et al. Low back pain and pelvic girdle pain in pregnancy. J Am Acad Orthop Surg 2015;23:539-49.

33 Evenson KR, Mottola MF, Owe KM, et al. Summary of international guidelines for physical activity after pregnancy. Obstet Gynecol Surv 2014;69:407-14.

34 Haakstad LAH, Voldner N, Bø K. Stages of change model for participation in physical activity during pregnancy. J Pregnancy 2013;193170.

35 Gustafsson MK, Romundstad PR, Stafne SN, et al. Alterations in the vitamin $\mathrm{D}$ endocrine system during pregnancy: a longitudinal study of 855 healthy Norwegian women. PLoS One 2018;13:e0195041.

36 Bannatyne AJ, Hughes R, Stapleton P, et al. Signs and symptoms of disordered eating in pregnancy: a Delphi consensus study. BMC Pregnancy Childbirth 2018;18:262. 